\title{
Flaubert hors de Babel, textes réunis par Michel Crouzet et Didier Philippot
}

\section{Ida Merello}

\section{(2) OpenEdition}

1 Journals

\section{Edizione digitale}

URL: http://journals.openedition.org/studifrancesi/1579

DOI: 10.4000/studifrancesi. 1579

ISSN: 2421-5856

\section{Editore}

Rosenberg \& Sellier

\section{Edizione cartacea}

Data di pubblicazione: 1 novembre 2014

Paginazione: 623-624

ISSN: 0039-2944

\section{Notizia bibliografica digitale}

Ida Merello, «Flaubert hors de Babel, textes réunis par Michel Crouzet et Didier Philippot », Studi

Francesi [Online], 174 (LVIII | III) | 2014, online dal 01 novembre 2014, consultato il 18 septembre 2020. URL : http://journals.openedition.org/studifrancesi/1579; DOI : https://doi.org/10.4000/studifrancesi. 1579

Questo documento è stato generato automaticamente il 18 settembre 2020.

\section{(c)}

Studi Francesi è distribuita con Licenza Creative Commons Attribuzione - Non commerciale - Non opere derivate 4.0 Internazionale. 


\title{
Flaubert hors de Babel, textes réunis par Michel Crouzet et Didier Philippot
}

\author{
Ida Merello
}

\section{NOTIZIA}

Flaubert hors de Babel, textes réunis par Michel CROUZET et Didier PHILIPPOT, Paris, Eurédit, 2013, pp. 264.

1 Jean-Louis CABANÈs, Sublime et réalisme dans les romans de Flaubert, pp. 33-55.

L'A. affronta la questione dibattuta della sublimità del personaggio stupido nelle opere di Flaubert. Dopo aver ricordato Boileau, che oppone il sublime dei «grands mots» al sublime della semplicità e della naturalezza, tanto più intenso perché conciso, mostra come Flaubert trasformi la congiunzione romantica del sublime e del grottesco in congiunzione "realista» del sublime e dell'ironia, attraverso l'uso dei silenzi e di dispositivi di scrittura, che attribuiscono una connotazione ironica a ciascuna delle valenze del sublime. Diversamente da Balzac e dai Goncourt, Flaubert non definisce mai sublime un gesto o una parola, ma avvalora di sublimità la semplicità e la concisione, sfumandole immediatamente attraverso elementi di mediocrità, che vi creano attorno un alone di ironia. L'A. riconosce la sublimità nei personaggi di Charles, di Félicité e di Dussardier, la cui bontà travalica i confini del quotidiano realista; ma mette in evidenza come i loro deficit intellettivi la riportino a una dimensione ironica. La vera ironia, e del tutto priva di sublimità, è invece riservata, secondo l'A., a Frédéric e Mme Arnoux, che si abbandonano senza autocritica a una retorica del sublime dei loro amori.

Eléonore ROY-REVERZY, La statue mutilée. Flaubert dans le naturalisme, pp. 57-82.

Il grande successo immediato di Flaubert, ha avuto, secondo l'A., da un lato, un effetto quasi paralizzante, dal momento che si trattava di un modello imprescindibile; dall'altro, ha portato a una serie di interpretazioni travisanti, nel momento in cui si 
tendeva a collocarlo nella corrente realista, tra Balzac e Zola. Inoltre Zola, attribuendogli il pregio di rifiutare l'enfasi balzacchiana, riduceva i suoi romanzi contemporanei a un appiattimento sul reale. Prende inizio qui quel fraintendimento che non tiene conto della volontà dell'estetica flaubertiana di adeguamento tra la parola e la cosa. L'A. distingue tra mimesis zoliana, complicata da elementi retorici per finalità diverse da quelle estetiche, e la poiesis di Flaubert, ossia di ricreazione a partire dalla profondità delle cose.

Didier PнILIPPOT, Flaubert et le mythe du «livre sur rien», pp. 83-143.

L'A. riflette sulla ricezione critica della famosa dichiarazione di Flaubert, individuando nelle interpretazioni novecentesche la sovrapposizione dell'estetica moderna della narrazione, con la morte del soggetto, e la disgregazione dell'intreccio. Mentre Zola attribuiva a Mme Bovary il merito di rinunciare al romanzesco in nome della piattezza della vita, la critica del Novecento tendeva a vedervi un'affermazione di autoreferenzialità. L'A. prende in esame i critici più significativi, per mostrare come il mito del libro sul nulla è andato costruendosi. Così J. Rousset considera i personaggi in sordina nei confronti dello stile, che funziona come la partitura di una sonata; G. Genette, vicino alla sensibilità di Blanchot, interpreta l'espressione flaubertiana come volontà di un libro senza soggetto, che manifesta il vuoto di trascendenza in un linguaggio pietrificato. Allo stesso modo l'Éducation sentimentale mostrerebbe la circolarità di una scrittura autoreferenziale e Bouvard et Pécuchet la direzione del romanzo verso la sua sparizione. A queste osservazioni, cui viene accostata la tesi recente di Sylvie Thorel-Cailleteau, su posizioni analoghe, l'A. ribatte riconducendo la frase di Flaubert all'estetica di Flaubert, per mostrare i suoi legami con il movimento dell'Arte per l'Arte e con Hegel. Lo stile costituisce allora un modo di essere e di pensare; mentre la filosofia di Hegel insegna non solo il rifiuto delle scuole, ma anche di ogni regola precostituita, in nome della libertà dello spirito. L'A. ribadisce il misticismo estetico di Flaubert, per cui il libro sul nulla rappresenta la volontà di non sottrarre l'Arte al suo carattere eterno per colpa di un eccesso di presenza del soggetto. Il concetto di stile di Buffon è utilizzato per confermare la qualità di fine e non di mezzo dell'espressione artistica, e il rifiuto flaubertiano di qualsiasi funzionalità dell'opera. Numerosi passaggi della Correspondance confermano del resto l'amore dell'assoluto della Forma, e il legame tra Bello e Vero (che è altresì all'origine del movimento romantico). Da ultimo l'A. cita i passi in cui Flaubert prende le distanze da Leconte de Lisle, colpevole di voler tornare all'antico, reintroducendo regole, in nome di una modernità peraltro antidemocratica. 